\title{
Acorus tatarinowii Schott extract reduces cerebral edema caused by ischemia- reperfusion injury in rats: involvement in regulation of astrocytic NKCC1/AQP4 and JNK/iNOS-mediated signaling
}

Yu-Chen Lee ${ }^{1,2,3}$, Shung-Te Kao ${ }^{4}$ and Chin-Yi Cheng ${ }^{5,6^{*}}$

\begin{abstract}
Background: This study aimed to evaluate the effects of the Acorus tatarinowii Schott [Shi Chang Pu (SCP)] extract administered at the start of $2 \mathrm{~h}$ of middle cerebral artery occlusion (MCAo), followed by $3 \mathrm{~d}$ of reperfusion, and to determine mechanisms involved in anti-edema effects in the penumbra of the cerebral cortex.

Method: Rats were intraperitoneally administered the SCP extract at a dose of $0.25 \mathrm{~g} / \mathrm{kg}$ (SCP- $0.25 \mathrm{~g}), 0.5 \mathrm{~g} / \mathrm{kg}$ (SCP$0.5 \mathrm{~g})$, or $1 \mathrm{~g} / \mathrm{kg}(\mathrm{SCP}-1 \mathrm{~g})$ at the start of MCAO.

Result: SCP-0.5 g and SCP-1 g treatments effectively reduced the cerebral infarct size, ameliorated cerebral edema, reduced blood-brain barrier permeability, and restored neurological function. SCP- $0.5 \mathrm{~g}$ and SCP-1 g treatments markedly downregulated the levels of glial fibrillary acidic protein, $\mathrm{Na}^{+}-\mathrm{K}^{+}-2 \mathrm{Cl}^{-}$cotransporter type 1 (NKCC1), aquaporin 4 (AQP4), phospho-c-Jun N-terminal kinase ( $p-J N K) / J N K$, inducible nitric oxide synthase (iNOS), 3nitrotyrosine, intercellular adhesion molecule-1 (ICAM-1), matrix metalloproteinase-9 (MMP-9), vascular endothelial growth factor-A (VEGF-A), and zonula occluden-1 (ZO-1) and upregulated ZO-3 expression in the penumbra of the cerebral cortex $3 \mathrm{~d}$ after reperfusion.
\end{abstract}

Conclusions: SCP- $0.5 \mathrm{~g}$ and SCP-1 g treatments exert neuroprotective effects against cerebral infarction and cerebral edema partially by mitigating astrocytic swelling and blood-brain barrier disruption. Moreover, the anticerebral edema effects of SCP extract treatments are possibly associated with the downregulation of astrocytic NKCC1/AQP4 and JNK/iNOS-mediated ICAM-1/MMP-9 signaling in the penumbra of the cerebral cortex $3 \mathrm{~d}$ after reperfusion.

Keywords: Acorus tatarinowii Schott, Cerebral edema, Aquaporin 4, C-Jun N-terminal kinase, Intercellular adhesion molecule-1, Zonula occluden-1

\footnotetext{
* Correspondence: c5398@ms22.hinet.net

${ }^{5}$ School of Post-baccalaureate Chinese Medicine, College of Chinese

Medicine, China Medical University, Taichung 40402, Taiwan

${ }^{6}$ Department of Chinese Medicine, Hui-Sheng Hospital 42056, Taichung,

Taiwan

Full list of author information is available at the end of the article
}

(c) The Author(s). 2020 Open Access This article is licensed under a Creative Commons Attribution 4.0 International License, which permits use, sharing, adaptation, distribution and reproduction in any medium or format, as long as you give appropriate credit to the original author(s) and the source, provide a link to the Creative Commons licence, and indicate if changes were made. The images or other third party material in this article are included in the article's Creative Commons. licence, unless indicated otherwise in a credit line to the material. If material is not included in the article's Creative Commons licence and your intended use is not permitted by statutory regulation or exceeds the permitted use, you will need to obtain permission directly from the copyright holder. To view a copy of this licence, visit http://creativecommons.org/licenses/by/4.0/ The Creative Commons Public Domain Dedication waiver (http://creativecommons.org/publicdomain/zero/1.0/) applies to the data made available in this article, unless otherwise stated in a credit line to the data. 


\section{Background}

The main pathological factors for ischemic stroke injury are inflammation and oxidative/nitrative stress, leading to the development of cerebral infarction and cerebral edema [1]. Accumulating evidence reveals that cerebral edema exacerbates cerebral injury and leads to the development of cerebral herniation, and these contribute to a high risk of death during ischemic stroke [2-4]. Based on the pathogenesis, cerebral edema is classified into two types: cytotoxic (intracellular) and vasogenic (extracellular) edema; edema results from water transport impairment in cells and blood vessels [2, 5]. Cerebral edema usually results from cytotoxic edema and subsequently progresses to vasogenic edema with a wide range of injuries [3].

Aquaporin 4 (AQP4), a member of the aquaporin family of membrane-bound proteins, is the most abundant water channel expressed in the perivascular astrocytic endfeet $[6,7]$. AQP4 enables the passive transport of water across membranes according to osmotic gradients. Water transport occurs from blood vessels to astrocytes or the brain parenchyma through AQP4, which regulates blood-brain barrier (BBB) permeability, and this is the rate-limiting step for water influx into the brain $[2,7,8]$. During cerebral ischemia-reperfusion (I/R) injury, AQP4 plays a crucial role in the pathophysiology of cytotoxic edema [6]. $\mathrm{Na}^{+}-\mathrm{K}^{+}-2 \mathrm{Cl}^{-}$cotransporter (NKCC) exists in two isoforms: NKCC1 and NKCC2. NKCC1 is present in a wide range of tissues, whereas NKCC2 is predominantly found in the kidney. NKCC1 plays a role in regulating water and ion homeostasis in astrocytes [9]. In the early phase of cerebral ischemia, the levels of intracellular $\mathrm{Ca}^{++}$and extracellular $\mathrm{K}^{+}$are markedly increased in the ischemia area; subsequently, this leads to NKCC1mediated $\mathrm{Na}^{+}, \mathrm{K}^{+}$, and $\mathrm{Cl}^{-}$transport and accompanying water influx into brain cells, leading to astrocytic swelling, cytotoxic edema, and cerebral infarction $[9,10]$. In addition, inhibition of NKCC1 expression in the ischemic region ameliorates brain swelling [8]. Under ischemic challenges, NKCC1- and AQP4-mediated astrocytic swelling leads to glutamate-mediated excitotoxicity, excessive nitric oxide (NO) production, and cytokine [such as interleukin (IL)-1 $\beta$, IL-6, and tumor necrosis factor- $\alpha$ ] release, which subsequently promote BBB disruption in the ischemic area, resulting in exacerbation of cerebral edema $[11,12]$. Thus, the expression of glial fibrillary acidic protein (GFAP), a marker of reactive astrogliosis, in the ischemic region is positively correlated with the severity of cerebral edema $[9,13,14]$.

Cerebral I/R injury induces the activation of c-Jun $\mathrm{N}$ terminal kinase (JNK), one of the mitogen-activated protein kinases (MAPKs), which subsequently upregulates the expression of inducible nitric oxide synthase (iNOS); this generates excessive amounts of reactive oxygen/nitrogen species, leading to oxidative/nitrative stress in the ischemic area [15-17]. iNOS upregulation in ischemic brain cells, including endothelial cells, initiates the nitrosylation of tyrosine-containing proteins, forming 3-nitrotyrosine (3-NT, a marker of nitrative stress), which causes the opening of mitochondrial permeability transition pores, and exacerbates postischemic inflammation and $\mathrm{BBB}$ damage $[18,19]$. Increased iNOS expression also enhances the synthesis of intercellular adhesion molecule-1 (ICAM-1) and matrix metalloproteinases (MMPs) (such as MMP-9) on endothelial cells $[20,21]$. MMP-9 plays a pivotal role in extracellular matrix degradation and BBB disruption, causing hemorrhage and vasogenic edema [21]. The cerebral $\mathrm{I} / \mathrm{R}$ injury-induced inflammatory response triggers $\mathrm{BBB}$ disruption and then increases $\mathrm{BBB}$ permeability, which upregulates vascular endothelial growth factor (VEGF) expression in the ischemic area [22, 23]. VEGF, a potent vascular permeability regulator, is positively related to the extent of vasogenic and cytotoxic edema in the acute phase of cerebral ischemic injury, whereas pharmacological inhibition of VEGF ameliorates vascular permeability and attenuates cerebral edema [3, 24]. Tight junction (TJ) proteins, which are major components of the $\mathrm{BBB}$, include the integral membrane proteins occludin and claudins; these membrane proteins interact with the plasma membrane of endothelial cells, forming the TJ barrier and determining endothelial permeability [24, 25]. Cytoplasmic TJ accessory proteins, such as zonula occluden (ZO)-1, -2 , and -3 , stabilize the $\mathrm{TJ}$ by binding occludin to the cytoskeleton [26]. Studies have showed that augmented expression of ICAM-1 and MMP-9 disrupts the endothelial $\mathrm{TJ}$ promoting the infiltration of activated leukocytes into the brain parenchyma and triggering vasogenic edema [18, 23].

Acorus tatarinowii Schott, commonly known as Shi Chang $\mathrm{Pu}(\mathrm{SCP})$, is a well-known traditional Chinese medicine widely used to treat stroke, dementia, depression, seizure, and mental disorders. SCP is also an ancient herbal supplement, and it exerts anti-fatigue effects [27, $28]$. Both $\alpha$-asarone and $\beta$-asarone are the main active components in SCP [29]. $\alpha$-Asarone enhances neural progenitor cell proliferation and differentiation into neuronal lineage cells and promotes neurofunctional recovery, as demonstrated in a mouse model of ischemic stroke [30]. $\beta$-Asarone can easily pass through the $\mathrm{BBB}$, and exerts neuroprotective effects on ischemic injury by downregulating Beclin-1-dependent autophagy in an in vitro model of oxygen-glucose deprivation/reperfusion-induced PC12 cells [31]. In addition, $\alpha$ - and $\beta$-asarone have neuroprotective effects against cerebral I/R injury by reducing glutamate- or N-methyl-D-asparate-induced excitotoxicity in the ischemic area after cerebral ischemia [32]. Studies have reported that the combination of $\alpha$ - and $\beta$-asarone at low 
dosages produces synergistic neurotrophic effects and prevents cytotoxic-induced side effects in cell culture models $[33,34]$. Moreover, $\beta$-asarone protects against cerebral I/R injury by stabilizing BBB integrity, and upregulating antioxidative and $\mathrm{Na}^{+}-\mathrm{K}^{+}$ATPase activities in the ischemic area in the acute phase of middle cerebral occlusion (MCAo) [35]. During cerebral I/R injury, BBB permeability, oxidative stress, and $\mathrm{Na}^{+}-\mathrm{K}^{+}$ATPase expression are closely associated with cerebral edema formation [36, 37]. Pharmacological restoration of BBB integrity and upregulation of $\mathrm{Na}^{+}-\mathrm{K}^{+}$ATPase activity effectively ameliorate cerebral edema in rat models of transient MCAo $[37,38]$. Based on the above findings, we speculate that SCP exerts anti-edema effects in a rat model of transient focal cerebral ischemia.

Thus, the aims of this study were to determine the anti-infarct, and anti-edema effects and mechanisms of the SCP extract administered at the start of MCAo, followed by $3 \mathrm{~d}$ of reperfusion.

\section{Methods}

\section{Experimental animals}

A total of 116 healthy male Sprague-Dawley rats (weight, 300-350 g; age, 8-9 wks) obtained from LASCO Co., Ltd. (I-Lan, Taiwan) were used in this study. The rats were housed in the animal room with the controlled conditions of $22-24^{\circ} \mathrm{C}$ and $50-55 \%$ relative humidity under a $12 / 12$ $\mathrm{h}$ light/dark cycle. Seven rats died during the experiments and the mortality rate was $6 \%$ in this study.

\section{Ethics statement}

All surgical and experimental procedures were approved by the Institutional Animal Care and Use Committee of China Medical University (Permit Number: CMUIACUC2018-304). The committee has recognized that the research methodologies and designs followed the Animal Protection Act by the Council of Agriculture, Taiwan. All surgical and experimental procedures were designed to avoid or minimize discomfort, distress, and pain to the animals.

\section{SCP extract preparation}

Two grams of SCP extract powder (Chuang Song Zong Pharmaceutical Co., Ltd., Taiwan) was dissolved in $8 \mathrm{~mL}$ double-distilled water. After stirring for $2 \mathrm{~min}$, the mixture was centrifuged at $1000 \times \mathrm{g}$ at $4{ }^{\circ} \mathrm{C}$ for $10 \mathrm{~min}$. The supernatant was collected in another tube, and the SCP aqueous extract was prepared at a final concentration of $0.125 \mathrm{~g} / \mathrm{mL}$.

High performance liquid chromatography measurement of the indicators of the SCP extract

The standards including $\alpha$-asarone (purity: $100 \%$, National Institutes for Food and Drug Control, China) and $\beta$-asarone (purity: 95.52\%, ChromaDex, USA) were accurately weighted and dissolved in pure methanol as the standard solutions. One and a half grams of the SCP extract powder was dissolved in $25 \mathrm{~mL}$ methanol, and the solution was centrifuged at $9000 \mathrm{rpm}$ at $4{ }^{\circ} \mathrm{C}$ for 10 min. The supernatant was collected as the test solution. Subsequently, High performance liquid chromatography (HPLC) analytical procedures were performed, as described previously [39]. Briefly, twenty microliters of the standard or test solution was injected into a Waters HPLC system (Waters Alliance 2695 Separations Module, Waters Corp.). The mobile phase consisted of water (A) and acetonitrile (B). In gradient elution, the percentage of mobile phase A was decreased from 75 to $25 \%$ for $50 \mathrm{~min}$, whereas the amount of mobile phase B was increased from 25 to $75 \%$. The flow rate was set at $1.0 \mathrm{~mL}$ per min, and the total run time was $50 \mathrm{~min}$. Absorbance was measured at $257 \mathrm{~nm}$.

\section{Transient MCAo}

MCAo was induced in the rats through the intraluminal suture occlusion technique, as previously described [39]. Briefly, the rats were anesthetized using isoflurane (5\% for induction and $2 \%$ for maintenance). The rat's head was fixed in a stereotactic frame, and the scalp was transversely dissected to expose the skull. Subsequently, a burr hole at a location $2.0 \mathrm{~mm}$ posterior and $2.5 \mathrm{~mm}$ lateral to the bregma was drilled into the skull for the assessment of blood flow in the right middle cerebral artery (MCA). After central neck dissection, the right external carotid artery (ECA) and internal carotid artery (ICA) were exposed. A 3-0 monofilament suture with a small round tip was gently inserted into the ICA through the ECA stump to occlude the origin of the MCA. Two hours after the induction of MCAo, the suture was carefully removed to allow reperfusion. During MCAo surgery, blood flow in MCA was assessed using Laser-Doppler flowmetry (DRT4, Moor Instruments Inc., USA). A decrease of greater than $80 \%$ in MCA blood flow in the phase of ischemia and an increase of greater than $60 \%$ in MCA blood flow in the phase of reperfusion verified the success of the MCAo model.

\section{Evaluation of neurological status}

The neurological status of each experimental rat was evaluated using the modified neurological severity score (mNSS) at 1 and $3 \mathrm{~d}$ after reperfusion. The mNSS described previously [40] includes scores of motor, sensory, balance, and reflex tests. The neurological deficit score ranges from 0 to 18 , with 0 as the normal condition and 18 as the maximal deficit score. 


\section{Experiment A \\ Grouping}

The rats were randomly divided into five groups: Sham $(n=5)$, Model $(n=5)$, SCP-0.25 g $(n=5)$, SCP-0.5 g $(n=5)$, and SCP-1 $\mathrm{g}(n=5)$ groups. The rats in the SCP$0.25 \mathrm{~g}, \mathrm{SCP}-0.5 \mathrm{~g}$, and SCP-1 g groups were intraperitoneally administered with the SCP extract at the doses of $0.25,0.5$, and $1 \mathrm{~g} / \mathrm{kg}$, respectively, at the onset of MCAo. After $2 \mathrm{~h}$ of ischemia followed by $3 \mathrm{~d}$ of reperfusion, the rats were anesthetized with $5 \%$ isoflurane. Each anesthetized rat was placed in a plastic chamber and then underwent $\mathrm{CO}_{2}$ euthanasia (flow rate: $5.5 \mathrm{~L} / \mathrm{min}$ ) until $60 \mathrm{~s}$ after breathing had stopped. Finally, the brain was quickly removed. The rats in the Model group were subjected to the same experimental procedures as those in the SCP-1 g group, but the rats were administered with normal saline instead of the SCP extract. The rats in the Sham group were subjected to the same experimental procedures as those in the Model group, but MCA was not occluded.

\section{Assessment of cerebral infarction}

After completing neurological examination at $3 \mathrm{~d}$ of reperfusion, the rats were anesthetized with $5 \%$ isoflurane and then underwent $\mathrm{CO}_{2}$ euthanasia, and their brains were quickly removed. The fresh brains were sectioned into $2 \mathrm{~mm}$-thick coronal slices, stained with 2,3,5-triphenyltetrazolium chloride (TTC; Merck, Germany) at $37^{\circ} \mathrm{C}$ for $5 \mathrm{~min}$, and then fixed with $4 \%$ paraformaldehyde overnight. In TTC staining, the white colored portion reveals the infarct area, whereas the dark-red colored portion reveals the non-infarct area. The percentage of the infarct area to the total coronal sectional area was calculated.

\section{Experiment B \\ Grouping}

The rats were randomly divided into five groups: Sham $(n=9)$, Model $(n=7)$, SCP-0.25 g $(n=7)$, SCP-0.5 g $(n=7)$, and SCP-1 g $(n=8)$ groups. The experimental procedures are the same as those for Experiment A.

\section{Measurement of water content in right cerebral hemispheres}

After $3 \mathrm{~d}$ of reperfusion, the rats were deeply anesthetized with $5 \%$ isoflurane $(3 \mathrm{~min})$; subsequently, their brains were quickly removed, and the cerebella were discarded. The right (ipsilateral) and left (contralateral) hemispheres along the anatomic midline were dissected. Cerebral edema was determined by measuring water content in right cerebral hemispheres through the wet and dry weight method. Each right cerebral hemisphere was weighted (wet weight) and subsequently placed in the oven set at $100^{\circ} \mathrm{C}$ for $24 \mathrm{~h}$ to obtain the dry weight.
The percentage of water content in right cerebral hemispheres was calculated using the following formula: $100 \times$ (wet weight-dry weight)/wet weight.

\section{Measurement of BBB permeability in the ischemic cortex} $\mathrm{BBB}$ permeability was determined using the previously described Evans blue dye (EBD) extravasation method with certain modifications [41]. Briefly, after $3 \mathrm{~d}$ of reperfusion, the rats were anesthetized. Two percent EBD solution (E2129 Sigma-Aldrich) was injected intravenously into each rat at a dose of $100 \mathrm{mg} / \mathrm{kg} 2 \mathrm{~h}$ before sacrifice. In the sacrifice procedure, the rats were deeply anesthetized with $5 \%$ isoflurane $(3 \mathrm{~min}$ ) and transcardially perfused with $0.9 \%$ saline to remove all intravascular dye, and their brains were quickly removed and coronally sectioned from -4.3 to $+1.7 \mathrm{~mm}$ of the bregma. The selected right (ischemic) cortex was homogenized with 1:2 volume of $50 \%$ trichloroacetic acid (T6399 Sigma-Aldrich) for $5 \mathrm{~min}$ and then incubated in a dark tube at $4{ }^{\circ} \mathrm{C}$ for $24 \mathrm{~h}$. Subsequently, the homogenates were centrifuged at $10000 \times \mathrm{g}$ for $25 \mathrm{~min}$ at room temperature $(\mathrm{RT})$, and the final supernatants were diluted with 1:3 volume of $95 \%$ ethanol for the spectrophotometric analysis of EBD (620 nm excitation/680 nm emission wavelengths).

\section{Experiment C Grouping}

The rats were randomly divided into five groups: Sham $(n=5)$, Model $(n=5)$, SCP-0.25 g $(n=5)$, SCP-0.5 g $(n=5)$, and SCP-1 $\mathrm{g}(n=5)$ groups. The experimental procedures are the same as those for Experiment A.

\section{Western blot analysis}

After $3 \mathrm{~d}$ of reperfusion, the rats were deeply anesthetized with $5 \%$ isoflurane ( $3 \mathrm{~min}$ ) and then sacrificed, and their brains were quickly removed. The brain samples were separated into the cortical penumbra fractions, which were further divided into cytosolic and mitochondrial fractions, as described previously [39]. Subsequently, $15 \mu \mathrm{g}$ proteins per well were loaded for $10 \%$ sodium dodecyl sulfate-polyacrylamide electrophoresis. After electrophoresis, the separated proteins were transferred onto nitrocellulose (NC) membranes, which were subsequently incubated with primary antibodies (Table 1) at $4{ }^{\circ} \mathrm{C}$ overnight. After washing, the $\mathrm{NC}$ membranes were incubated with appropriate secondary antibodies (1:5000 dilution) at RT for $1 \mathrm{~h}$. Protein bands were revealed using the enhanced chemiluminescence plus reagent solution (GE Healthcare). The band intensity of target protein expression levels in relation to actin (or nonphosphorylated target protein) was calculated using ImageJ software (NIH, Bethesda, MD, USA). 
Table 1 Primary antibodies used in this study

\begin{tabular}{|c|c|c|c|c|}
\hline Species & Primary antibody & Western blotting Dilution & $\begin{array}{l}\text { Immunohistochemistry } \\
\text { (Immunofluorescence) Dilution }\end{array}$ & Source \\
\hline Mouse & GFAP & $1: 1000$ & $(1: 100)$ & CST/\#3670 \\
\hline Rabbit & NKCC1 & $1: 1000$ & $1: 200(1: 100)$ & abcam/ab59791 \\
\hline Rabbit & phospho-JNK (p-JNK) & $1: 1000$ & & CST/\#9251 \\
\hline Rabbit & JNK & $1: 1000$ & & CST/\#9252 \\
\hline Rabbit & iNOS & $1: 250$ & & abcam/ab15323 \\
\hline Rabbit & VEGF-A & 1:1000 & & Proteintech/\#19,003-1-AP \\
\hline Rabbit & ZO-1 & $1: 1000$ & 1:200 (1:100) & abcam/ab96587 \\
\hline Rabbit & ZO-2 & 1:1000 & & CST/\#2847 \\
\hline Rabbit & ZO-3 & $1: 1000$ & & abcam/ab191143 \\
\hline Mouse & 3-NT & & 1:1000 & abcam/ab61392 \\
\hline Mouse & AQP4 & & 1:100 (1:50) & abcam/ab9512 \\
\hline Mouse & ICAM-1 & & $1: 100(1: 50)$ & abcam/ab171123 \\
\hline Rabbit & MMP-9 & & 1:400 & abcam/ab137867 \\
\hline Mouse & Actin & $1: 5000$ & & NB/NB600-501 \\
\hline
\end{tabular}

CST Cell Signaling Technology, NB Novus Biologicals

\section{Experiment D Grouping}

The rats were randomly divided into five groups: Sham $(n=4)$, Model $(n=4)$, SCP-0.25 g $(n=4)$, SCP$0.5 \mathrm{~g} \quad(n=5)$, and SCP-1 g $(n=4)$ groups. The experimental procedures are the same as those for Experiment A.

\section{Immunohistochemical analysis}

After $3 \mathrm{~d}$ of reperfusion, the rats were anesthetized with $5 \%$ isoflurane and then underwent $\mathrm{CO}_{2}$ euthanasia; subsequently, the rats were transcardially perfused with saline $(0.9 \% \mathrm{NaCl})$. Their brains were quickly removed, embedded in the optimal cutting temperature compound, frozen, cut into $15 \mu \mathrm{m}$-thick coronal sections, and subsequently incubated with normal serum, as described previously [42]. The brain sections were incubated with primary antibodies (Table 1) at $4{ }^{\circ} \mathrm{C}$ overnight. The sections were subsequently incubated with appropriate secondary antibodies and avidin-biotin peroxidase complexes (Leica Biosystems Newcastle Ltd., UK). In all sections, immunopositive cells in the penumbra of the cerebral cortex were calculated in each of nine $400 \times$ magnification fields ( 1 $\mathrm{mm}^{2}$ ) under a light microscope (Axioskop 40, Zeiss). The adjacent sections from the Model group without primary antibody staining were used as negative controls.

\section{Assessment of immunofluorescence double staining}

The brain sections were incubated with $5 \%$ bovine serum albumin in phosphate buffered saline/Tween $20(0.01 \%)$ (PBST) for $30 \mathrm{~min}$ at RT and were subsequently incubated with rabbit and mouse primary antibodies (Table 1) overnight at $4{ }^{\circ} \mathrm{C}$. After washing three times with PBST, the brain sections were stained with DyLight 594-conjugated (1:200 dilution, Jackson ImmunoResearch) and 488-conjugated (1:200 dilution, Jackson ImmunoResearch) IgG secondary antibodies for $1 \mathrm{~h}$ at $37^{\circ} \mathrm{C}$. Immunopositive cells in the penumbra of the cerebral cortex were detected in each of nine $400 \times$ magnification fields $\left(1 \mathrm{~mm}^{2}\right)$ under a fluorescence microscope (CKX53, Olympus, Tokyo, Japan).

\section{Statistical analysis}

All data are represented as the mean \pm standard deviation. Statistical analysis of the data in this study was performed using one-way analysis of variance. Comparisons among experimental groups were made using the Scheffe test. A $P$ value less than 0.05 indicated statistically significant differences.

\section{Result}

\section{HPLC analysis of SCP extract}

For both the standard solution and SCP extract solution, the retention times of $\beta$-asarone and $\alpha$-asarone were about 26.8 and $28.5 \mathrm{~min}$, respectively. $\beta$-Asarone and $\alpha$-asarone contents in the SCP extract were 0.16 and $0.01 \mathrm{mg} / \mathrm{g}$, respectively (Fig. $1 \mathrm{a}$ and b).

\section{Effects of SCP treatments on cerebral infarction}

After $3 \mathrm{~d}$ of reperfusion, the cerebral infarct areas were evaluated through TTC staining. The percentage of cerebral infarct areas markedly increased in the Model group compared with the Sham group $(P<0.05)$ and markedly decreased in the SCP-0.5 $\mathrm{g}$ and SCP- $1 \mathrm{~g}$ groups compared with the Model group (both $P<0.05$; Figs. 2 and 3a). No 


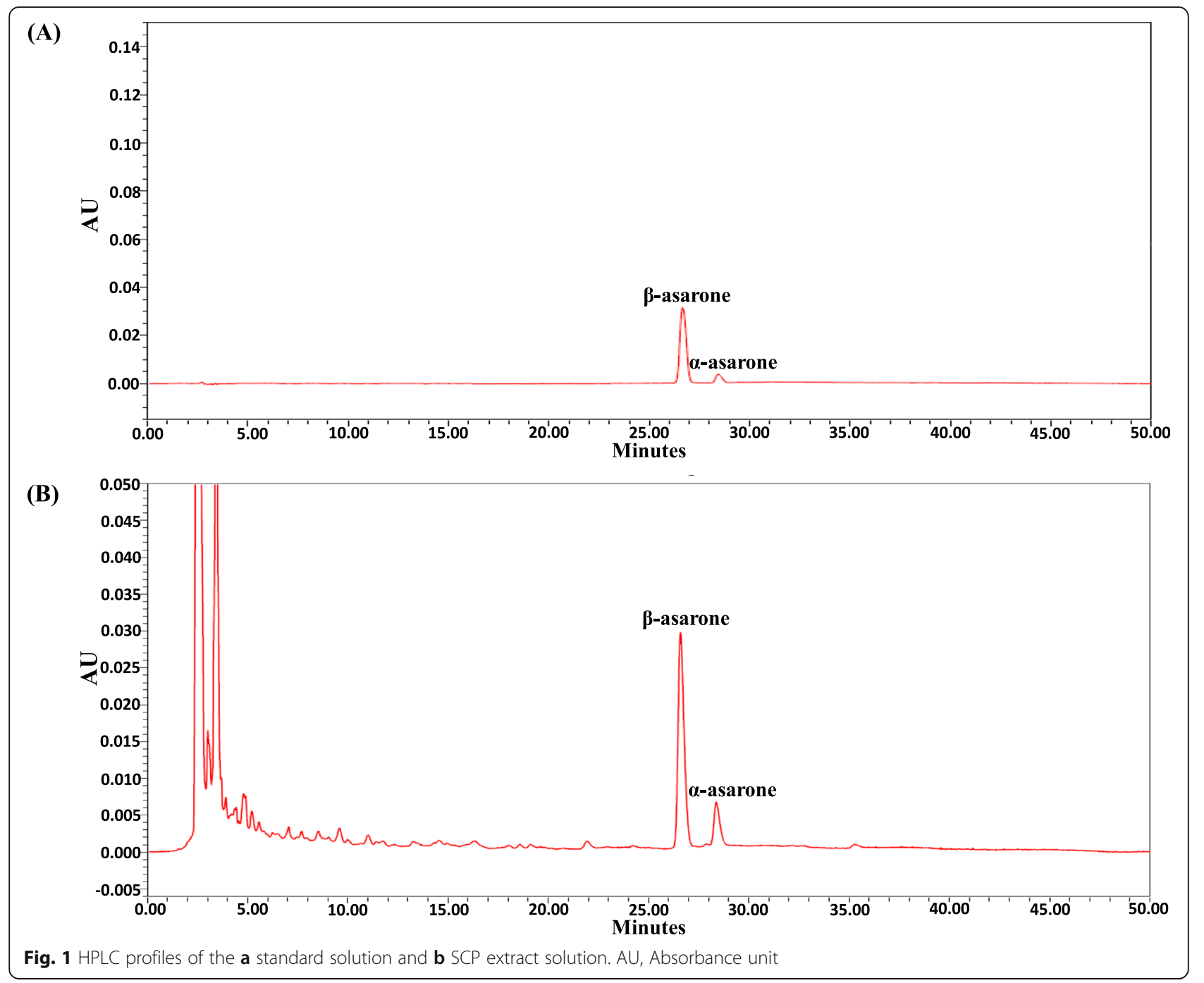

marked difference was found in the percentage of cerebral infarct areas between the Model and SCP- $0.25 \mathrm{~g}$ groups $(P>0.05)$.

\section{Effects of SCP treatments on neurological status}

After 1 and $3 \mathrm{~d}$ of reperfusion, the neurological deficit scores markedly increased in the Model group compared with the Sham group (both $P<0.05$ ) and markedly decreased in the SCP- $0.5 \mathrm{~g}$ and SCP-1 $\mathrm{g}$ groups compared with the Model group (all $P<0.05$; Fig. 3b). However, no marked difference was found in the neurological deficit scores between the Model and SCP- $0.25 \mathrm{~g}$ groups $(P>0.05)$.

\section{Effects of SCP treatments on water content in right cerebral hemispheres}

Three days after reperfusion, water content in right (ipsilateral) cerebral hemispheres was measured using the tissue drying method. The percentage of water content in right cerebral hemispheres markedly increased in the Model group compared with the Sham group $(P<0.05)$ and markedly decreased in the SCP- $0.5 \mathrm{~g}$ and SCP- $1 \mathrm{~g}$ groups compared with the Model group (both $P<0.05$; Fig. 3c). However, No marked difference was found in the percentage of water content in right cerebral hemispheres between the Model and SCP-0.25 g groups $(P>0.05)$.

\section{Effects of SCP treatments on BBB permeability in right cortical regions}

BBB permeability in the selected right cortical regions markedly increased in the Model group (6.7-fold) compared with the Sham group $(P<0.05)$ and markedly decreased in the SCP- $0.5 \mathrm{~g}$ (0.3-fold) and SCP-1 (0.3fold) g groups compared with the Model group $3 \mathrm{~d}$ after reperfusion (both $P<0.05$; Fig. $4 \mathrm{a}-\mathrm{C}$ ). However, no marked difference was found in BBB permeability in the 


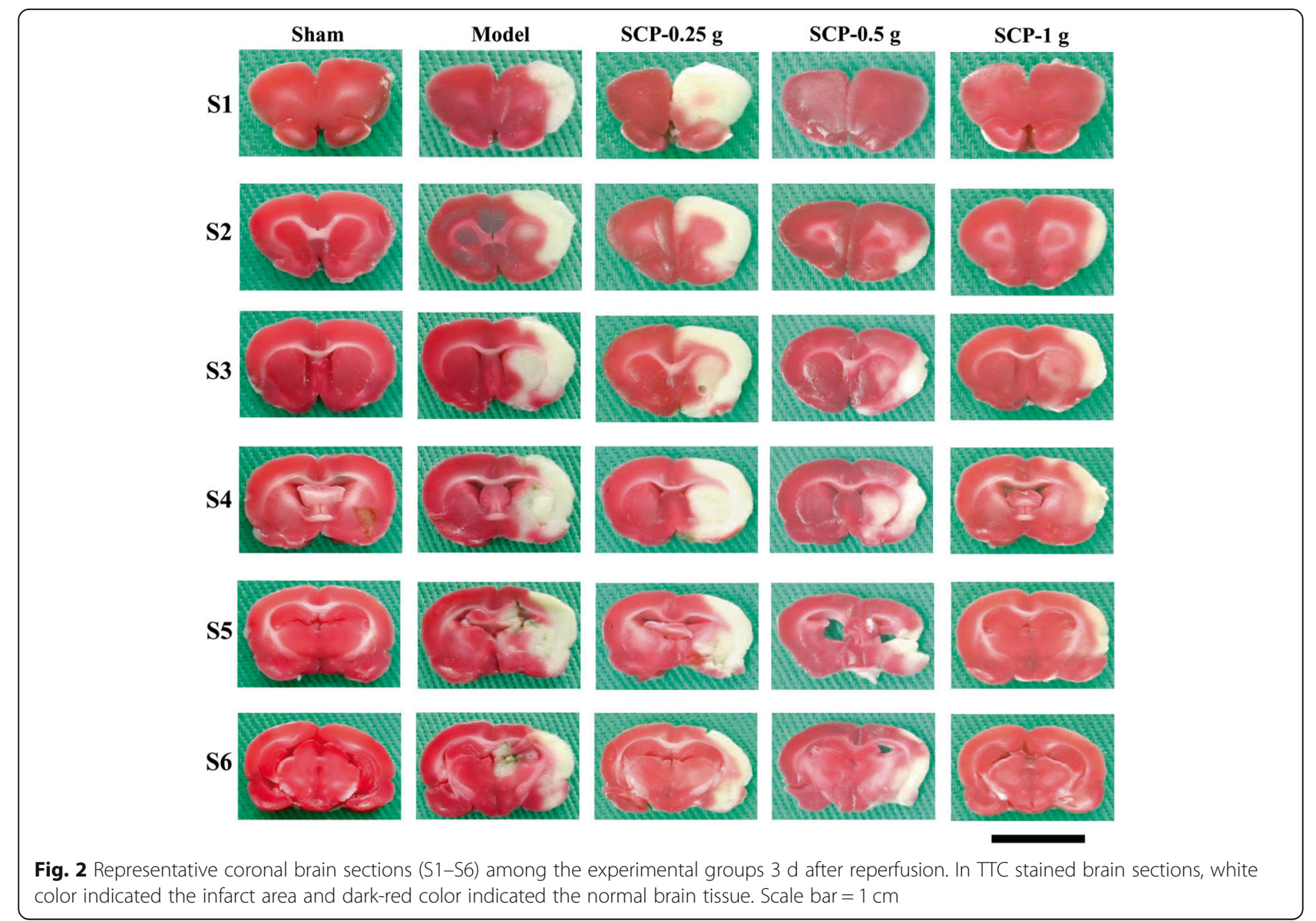

selected right cortical regions between the Model and SCP-0.25 g groups $(P>0.05)$.

\section{Effects of SCP treatments on the cytosolic expression of GFAP, NKCC1, and p-JNK/JNK}

The cytosolic expression of GFAP/actin, NKCC1/actin, and $\mathrm{p}-\mathrm{JNK} / \mathrm{JNK}$ in the penumbra of the cerebral cortex markedly increased in the Model group (13.2-, 3.4-, and 3.2 -fold, respectively) compared with the Sham group (all $P<0.05$ ) and markedly decreased in the SCP- $0.5 \mathrm{~g}$ (0.1-, 0.4-, and 0.4-fold, respectively) and SCP-1 g (0.1-, 0.3-, and 0.3-fold) groups compared with the Model group $3 \mathrm{~d}$ after reperfusion (all $P<0.05$; Fig. 5a-d). However, the aforementioned protein levels showed no marked difference between the Model and SCP- $0.25 \mathrm{~g}$ groups $(P>0.05)$.

\section{Effects of SCP treatments on the cytosolic expression of iNOS, VEGF-A, ZO-1, ZO-2, and ZO-3}

The cytosolic expression of iNOS/actin, VEGF-A/ actin, and $\mathrm{ZO}-1 /$ actin in the penumbra of the cerebral cortex markedly increased in the Model group (3.3-, 2.5-, and 5.5-fold, respectively) compared with the Sham group (all $P<0.05$ ) and markedly decreased in the SCP-0.5 g (0.4-, 0.4-, and 0.2-fold, respectively) and SCP-1 g (0.4-, 0.6-, and 0.2-fold, respectively) groups compared with the Model group 3 d after reperfusion (all $P<0.05$; Fig. 6a-d). By contrast, the cytosolic expression of ZO-3/actin in the penumbra of the cerebral cortex markedly decreased in the Model group (0.4-fold) compared with the Sham group $(P<0.05)$ and markedly increased in the SCP-0.5 g (2.0-fold) and SCP-1 g (2.5-fold) groups compared with the Model group (both $P<0.05$; Fig. $6 \mathrm{a}$ and $\mathrm{f}$ ). However, the aforementioned protein levels showed no marked difference between the Model and SCP-0.25g groups $(P>0.05)$. The cytosolic expression of $\mathrm{ZO}-2 /$ actin showed no marked difference among the experimental groups $(P>0.05$; Fig. 6a and e).

Effects of SCP treatments on AQP4, NKCC1, 3-NT, ICAM-1, ZO-1, and MMP-9 expression

The numbers of AQP4-, NKCC1-, 3-NT-, ICAM-1-, ZO1-, and MMP-9-positive cells were measured within the dotted line square in the penumbra of the cerebral cortex (counts $/ 1 \mathrm{~mm}^{2}$; Fig. $7 \mathrm{c}$ ) $3 \mathrm{~d}$ after reperfusion. The numbers of these immunopositive cells markedly increased in 


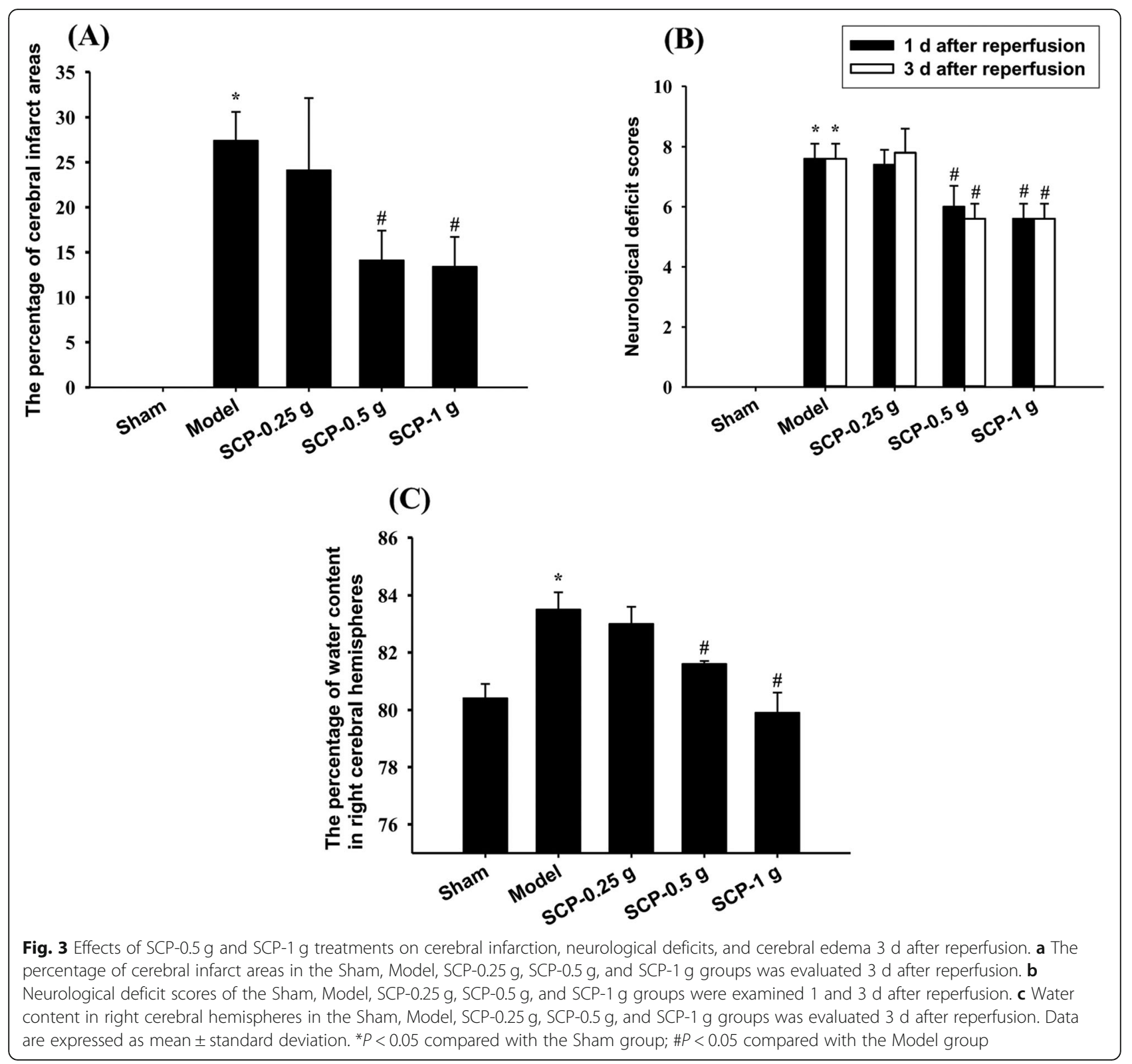

the Model groups compared with the Sham group (all $P<$ 0.05 ) and markedly decreased in the SCP-0.5 g and SCP-1 g groups compared with the Model group (all $P<0.05$; Figs. 7a, b, d, e, 8a-d, and 9a-d). However, the aforementioned immunopositive cells showed no marked difference between the Model and SCP-0.25 g groups $(P>0.05)$.

Expression of GFAP- and NKCC1-positive cells and AQP4/ NKCC1 and ICAM-1/ZO-1 double-labeled cells in the cortical penumbra

GFAP-, NKCC1-, and AQP4-immunopositive cells were predominantly observed in the penumbra of the cerebral cortex $3 \mathrm{~d}$ after reperfusion (Fig. 10a, b, d, and e). The expression levels of NKCC1 were positively correlated with those of GFAP (Fig. 10c). AQP4 was colocalized with NKCC1 in the cortical penumbra (Fig. 10d-f). In addition, ZO-1 was predominantly expressed in vascular endothelial cells and was colocalized with ICAM-1 (Fig. 10g-i).

\section{Discussion}

Inflammatory responses and oxidative/nitrative stress are the main pathological characteristics of $\mathrm{I} / \mathrm{R}$-induced cerebral infarction, which is closely associated with BBB disruption and astrocyte activation; these are followed by cerebral edema in the early phase of ischemic stroke [1, 


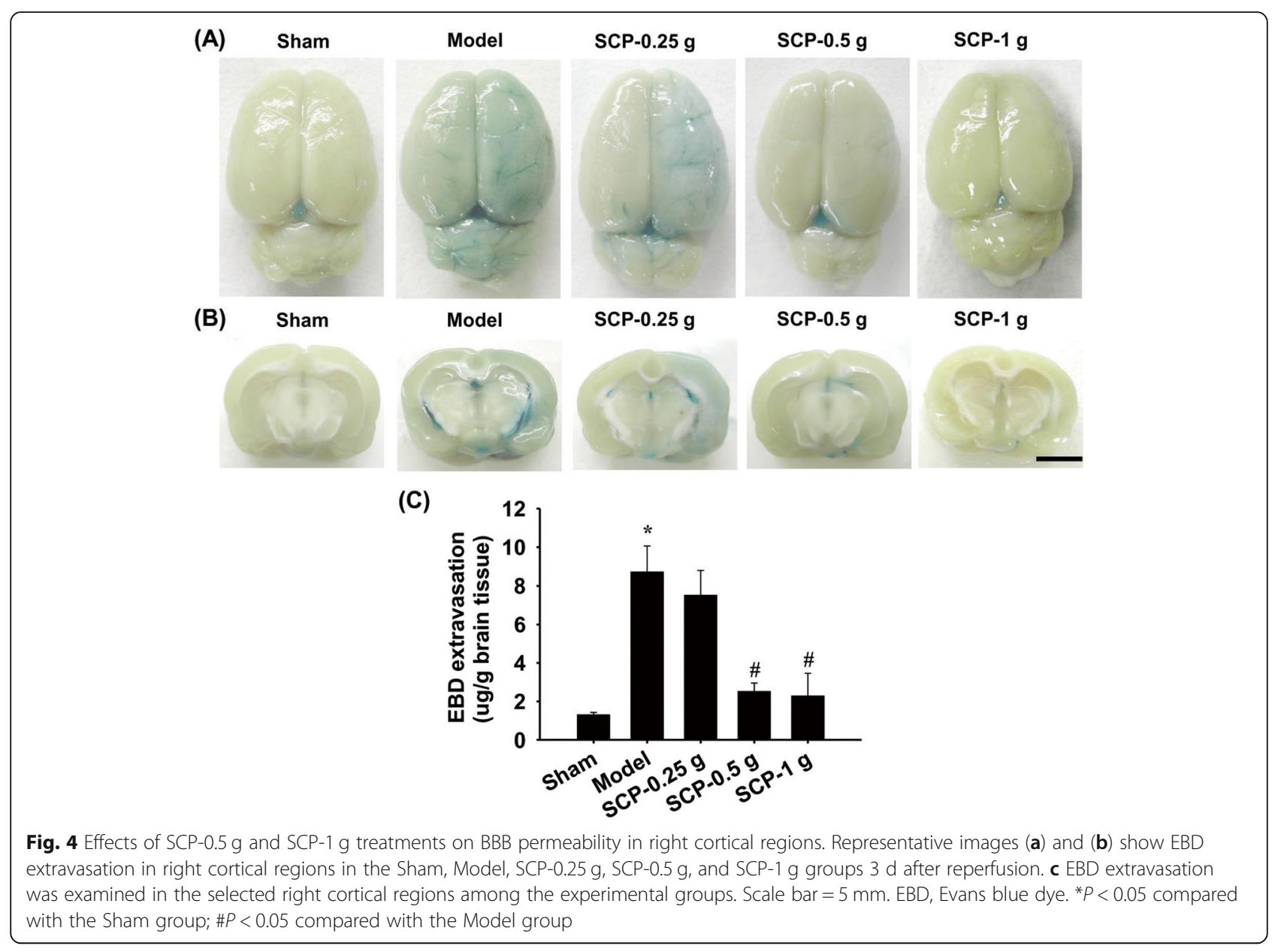

43, 44]. Previous studies have reported that cerebral edema initiated as early as $3-6 \mathrm{~h}$ and maintained at a high level until $72 \mathrm{~h}$ after reperfusion exacerbates cerebral infarction during the acute phase of focal cerebral ischemia [4, 45]. In this study, the TTC staining results revealed that prominent infarction occurred in the right cerebral hemisphere including the cortex and striatum 3 $\mathrm{d}$ after reperfusion. However, the SCP extract administered at doses of $0.5 \mathrm{~g} / \mathrm{kg}$ (SCP- $0.5 \mathrm{~g})$ and $1 \mathrm{~g} / \mathrm{kg}$ (SCP-1 $\mathrm{g}$ ), but not $0.25 \mathrm{~g} / \mathrm{kg}$ (SCP- $0.25 \mathrm{~g}$ ), markedly reduced cerebral areas and effectively restored neurological function. In addition, SCP- $0.5 \mathrm{~g}$ and SCP- $\mathrm{g}$ treatments markedly reduced water content in the right cerebral hemisphere. During the early stage of cerebral I/R injury, the upregulated expression of reactive astrogliosis in the ischemic penumbra is closely associated with the extension of cerebral infarction and cerebral edema [13, 39, 42, 46]. Our Western blot results showed that the expression of GFAP, a marker of reactive astrocytes, was markedly elevated in the penumbra of the cerebral cortex $3 \mathrm{~d}$ after reperfusion, whereas SCP- $0.5 \mathrm{~g}$ and SCP- $1 \mathrm{~g}$ treatments effectively reduced the elevated expression of GFAP in the peri-infarct area. Based on these results, we suggest that SCP- $0.5 \mathrm{~g}$ and SCP- $1 \mathrm{~g}$ treatments effectively reduce cerebral infarction, improve neurological function, and ameliorate cerebral edema $3 \mathrm{~d}$ after reperfusion. Furthermore, the neuroprotective effects of SCP extract treatments against cerebral $\mathrm{I} / \mathrm{R}$ injury are at least partially due to the inhibition of reactive astrocytemediated infarct expansion and cerebral edema in the early phase of transient MCAo.

Reactive astrocytes are important participants in cerebral edema due to overexpression of water transport proteins during cerebral I/R injury [13]. Under cerebral ischemic conditions, the deprivation of ATP and decreased activity of $\mathrm{Na}^{+} / \mathrm{K}^{+}$-ATPase results in the transport of $\mathrm{Na}^{+}$ions into neurons and glial cells; subsequently, the entry of $\mathrm{Na}^{+}$ions causes $\mathrm{Cl}^{-}$ions influx through chloride channels, which leads to an increase in plasma osmolarity of cells [11, 47]. In addition, glutamate-induced elevated levels of extracellular $\mathrm{K}^{+}$ions trigger NKCC1 activation, which 


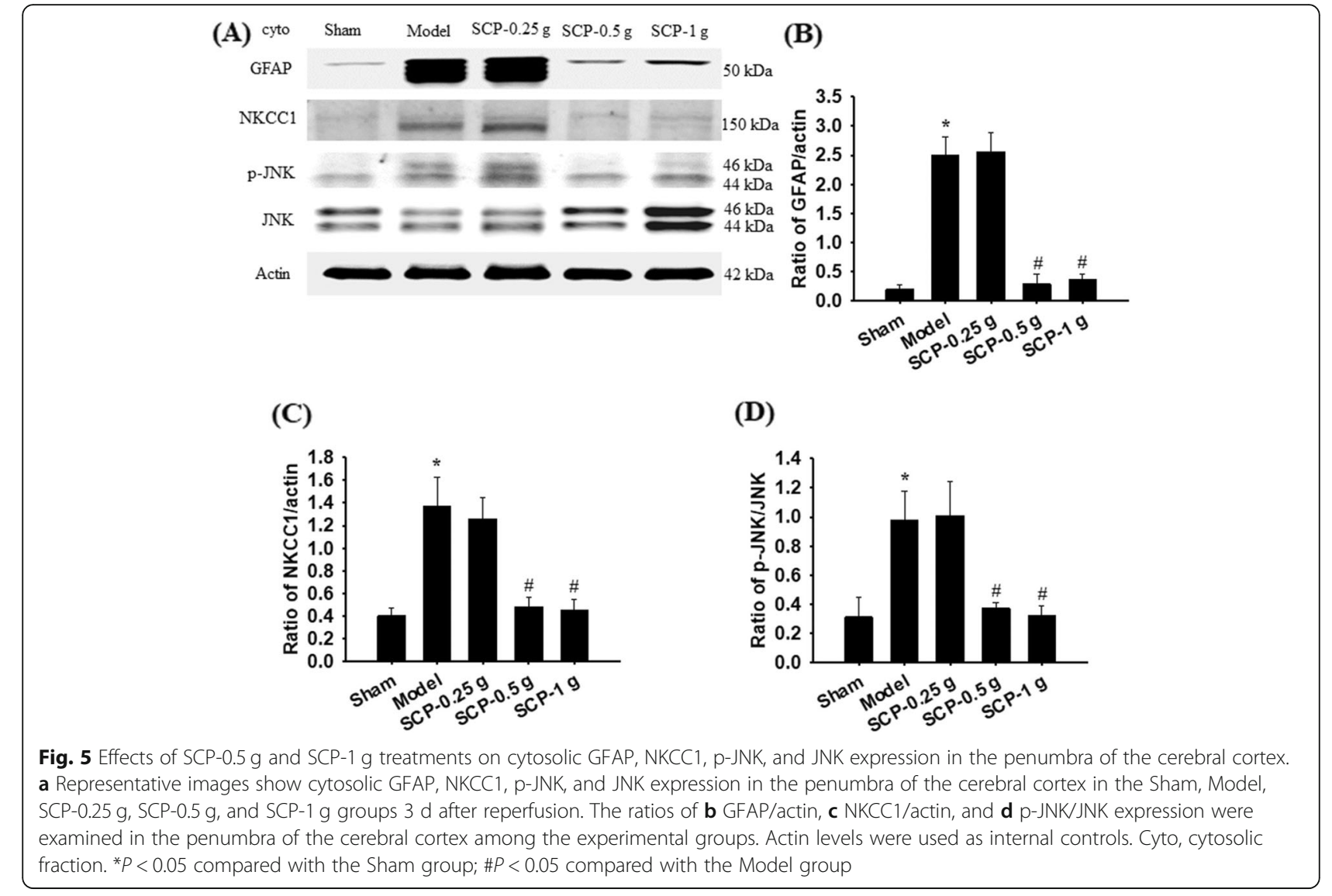

moves one $\mathrm{Na}^{+}$, one $\mathrm{K}^{+}$, and two $\mathrm{Cl}^{-}$ions into the astrocyte, enhancing the intracellular osmotic pressure and accompanying water influx [8]. AQP4, a waterspecific transport protein, plays a crucial role in the movement of water into and out of the brain parenchyma. During MCAo, AQP4 is prominently expressed in the glial limitans and astrocyte endfeet covering the endothelial cells of the $\mathrm{BBB}$, which subsequently facilities water passage into the astrocytes according to osmotic gradients, leading to astrocytic swelling (cytotoxic edema) within $24-72 \mathrm{~h}$ after the initiation of the cerebral ischemic insult [13, 48]. Pharmacological inhibition of NKCC1 or AQP4 expression in the ischemic area effectively reduced the infarct size and ameliorated cerebral edema in rat models of transient [49] and permanent [50, 51] MCAo. Our Western blot assay, immunohistochemical (IHC), and immunofluorescence (IF) double staining results revealed that AQP4 was colocalized with NKCC1, which was consistent with the elevation of GFAP expression in the cortical penumbra. Furthermore, the expression levels of NKCC1 and AQP4 were significantly increased in the penumbra of the cerebral cortex $3 \mathrm{~d}$ after reperfusion. However, SCP-
$0.5 \mathrm{~g}$ and SCP-1 $\mathrm{g}$ treatments effectively attenuated the expression of these proteins. The present findings indicate that the neuroprotective effects of SCP extract treatments on cerebral edema are partially due to the inhibition of astrocytic swelling in the cortical penumbra. Furthermore, the anti-cytotoxic edema effects of SCP extract treatments are partially attributed to the downregulation of astrocytic NKCC1/AQP4 signaling $3 \mathrm{~d}$ after reperfusion.

In cerebral I/R injury, NKCC1- and AQP4-mediated astrocytic swelling triggers JNK activation, which subsequently induces oxidative/nitrative stress and pro-inflammatory cytokine production, resulting in disruption of $\mathrm{BBB}$ integrity and exacerbation of cerebral edema $[11,12,52]$. JNK, one of the MAPK family members, participates in various cerebral $I / R$ insults and plays a pivotal role in inflammation and apoptosis. Accumulated evidence indicates that the activation of JNK signaling triggers subsequent iNOSinduced NO overproduction during cerebral I/R injury $[17,53]$. Large amounts of NO react rapidly with superoxide anions to produce high levels of peroxynitrite, which causes the nitration of tyrosine resides to form 3-NT (a footprint of peroxynitrite production) 


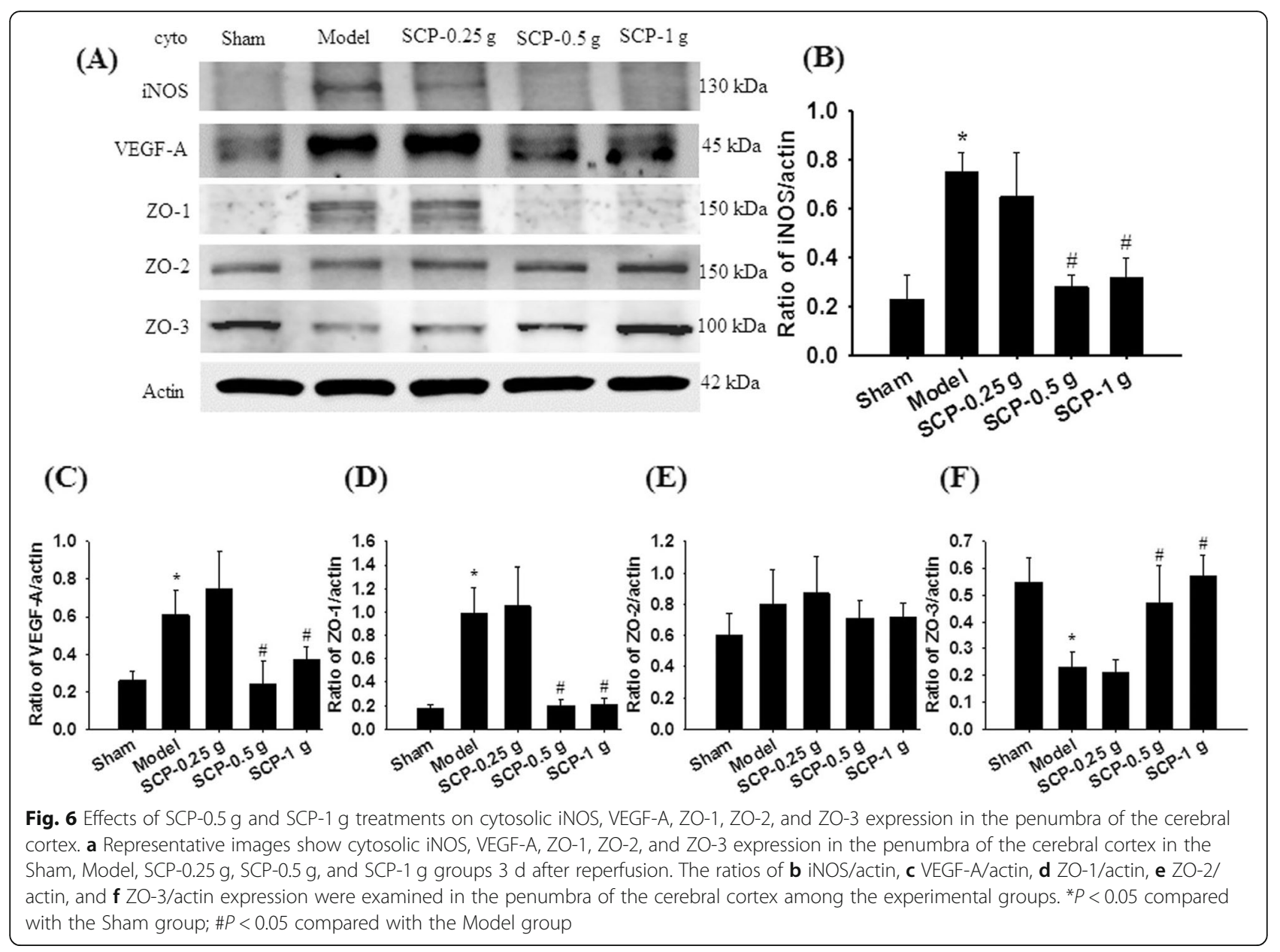

in the cell membrane and organelles [26]. The robust expression of iNOS and 3-NT is present in the ischemic area as early as $24 \mathrm{~h}$ and up to $96 \mathrm{~h}$ after cerebral reperfusion [16, 54]. Oxidative/nitrative stress causes the upregulation of adhesive molecules, such as ICAM-1, triggers leukocyte infiltration into the infarct area, and causes endothelial dysfunction, resulting in BBB disruption and initiating vasogenic edema formation in the early phase of ischemic stroke [15]. In addition, peroxynitrite-mediated oxidative/nitrative stress increases the expression of MMP-9 in endothelial cells, augmenting I/R-induced inflammatory responses and exacerbating BBB disruption [18]. Thus, a close relationship exists between oxidative/nitrative stress and MMP-9 in the pathology of BBB disruption. Furthermore, MMP-9 activation leads to degradation of TJs in endothelial cells and finally increases $\mathrm{BBB}$ permeability in the ischemic region [55]. VEGFA, a VEGF family member, plays a key role in angiogenesis and vascular permeability. VEGF-A can regulate the expression of components of $\mathrm{TJ}$ proteins in endothelial cells through the activation of MMPs, and it is positively associated with BBB disruption and cerebral edema in the acute phase of cerebral ischemia [24, 39]. Previous studies have reported that vasogenic edema occurs as early as $4 \mathrm{~h}$ and reaches a peak at $24-72 \mathrm{~h}$ after the onset of ischemia $[18,55]$. Therapeutic agents that inhibit JNK activation and reduce iNOS, 3-NT, ICAM-1, MMP-9, and VEGF expression in the ischemic region effectively restore BBB integrity, reduce the cerebral infarct area, and ameliorate vasogenic edema in rat models of cerebral $\mathrm{I} / \mathrm{R}$ injury $[15,16,18,24,55]$. Brain water content and $\mathrm{BBB}$ permeability can be assessed as the indicators of vasogenic edema induced by $I / R$ injury [56]. In the present study, water content and BBB permeability in the selected ischemic regions were markedly increased $3 \mathrm{~d}$ after reperfusion, a finding consistent with those of the aforementioned studies [18, 55]. However, SCP-0.5 g and SCP-1 g treatments effectively restored water content and $\mathrm{BBB}$ permeability in the selected ischemic regions. Moreover, our Western blot 


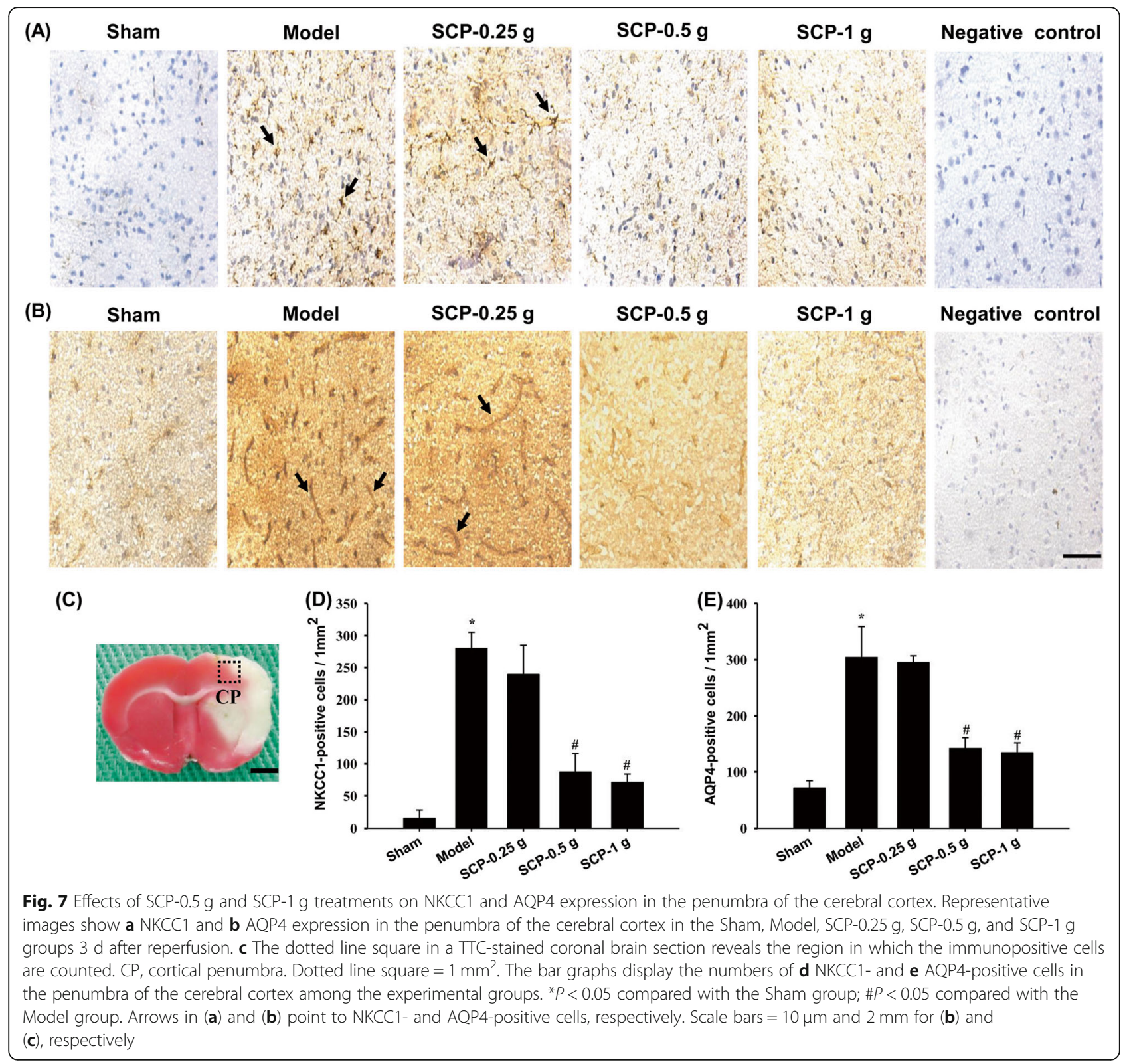

and IHC findings showed that the expression levels of p-JNK/JNK ratio, iNOS, 3-NT, ICAM-1, MMP-9, and VEGF-A were markedly upregulated in the penumbra of the cerebral cortex, whereas SCP extract treatments effectively downregulated the expression of the aforementioned proteins $3 \mathrm{~d}$ after reperfusion. On the basis of these results, we suggest that SCP extract treatments protect against cerebral I/R-induced BBB damage partially by downregulating the astrocytic swelling-mediated JNK/iNOS signaling pathway in the cortical penumbra. Furthermore, the anti-vasogenic edema effects of SCP extract treatments are partially due to the downregulation of JNK/iNOS-mediated
ICAM-1/MMP-9/VEGF-A signaling 3 d after reperfusion.

Previous studies have demonstrated that the increase in BBB permeability and the disruption of $\mathrm{BBB}$ integrity are positively related to cerebral edema [3, 24]. The BBB is composed of endothelial cells that represent capillaries in the brain parenchyma, and $\mathrm{TJ}$ offers an effective barrier between the endothelial cells [57]. The main proteins embedded in the membrane of the endothelial $\mathrm{TJ}$ are claudins, occludin, and $\mathrm{ZO}$ [58]. Cytoplasmic TJ accessory proteins including ZO-1, -2 , and -3 form and stabilize the TJ barrier by connecting occludin to the actin 


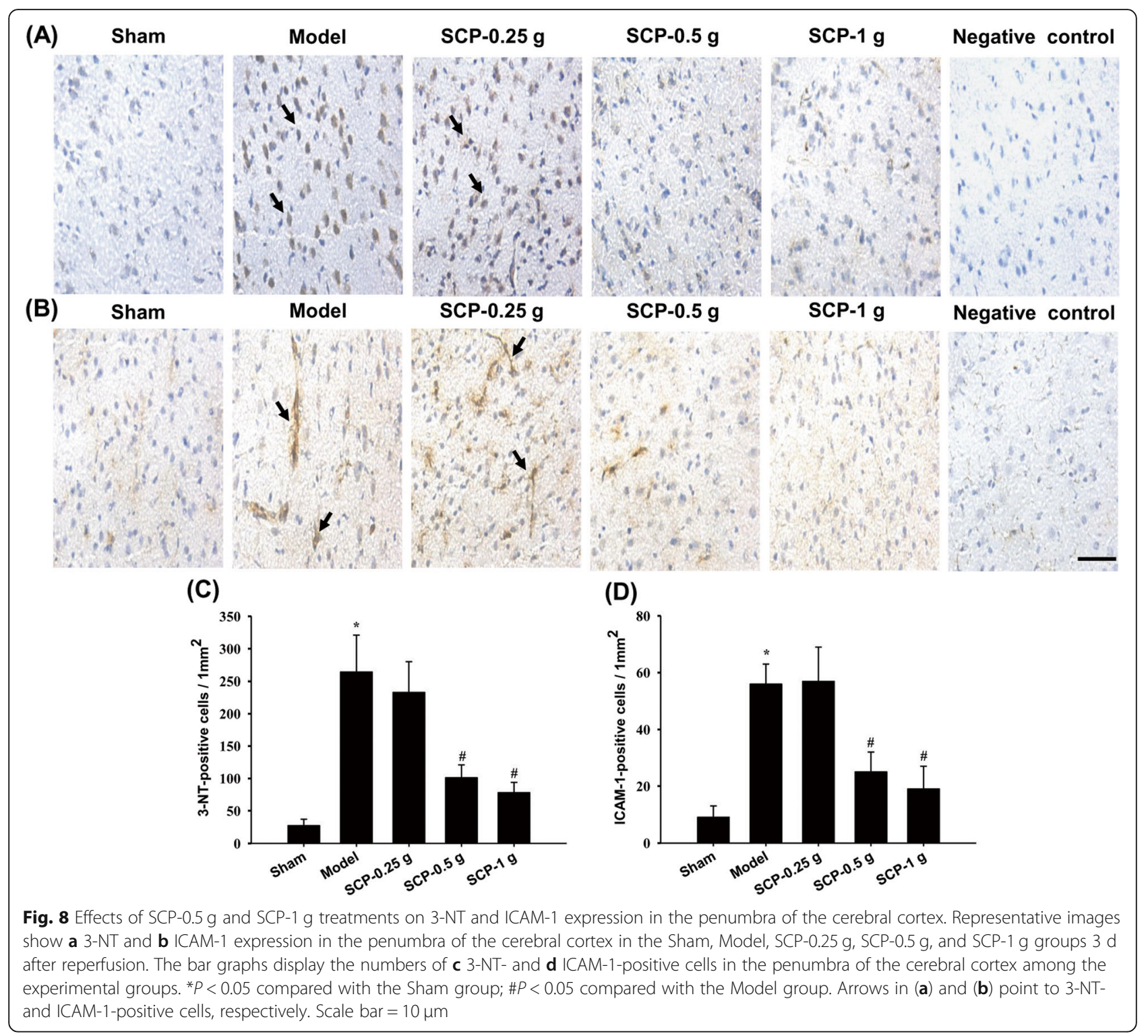

cytoskeleton [59]. Furthermore, in the molecular structure of TJ proteins, ZO-1/ZO-2 and ZO-1/ZO-3 heterodimers are directly involved in the regulation of the barrier function of TJs [60]. A previous study reported that ZO-1 plays dual roles in the promotion of $\mathrm{TJ}$ integrity and endothelial chemotaxis in an in vitro model of sphingosine-1-phosphate-treated vascular endothelial cells [61]. Zan et al. (2014) conduced the time-course expression analysis of the TJ protein and revealed that the expression of ZO-1 mRNA and protein was significantly decreased in the ischemic area $1 \mathrm{~d}$ but gradually increased 3-7 d after cerebral I/R [62]. In addition, previous results revealed that pharmacological upregulation of $\mathrm{ZO}-1$ expression exerts neuroprotective effects against cerebral infarction and cerebral edema by preserving endothelial TJ integrity in the ischemic area $1 \mathrm{~d}$ after reperfusion $[3,57,62]$. The results of this study showed that the expression of $\mathrm{ZO}-1$ markedly increased in the cortical penumbra, whereas the expression of $\mathrm{ZO}-3$ significantly decreased $3 \mathrm{~d}$ after reperfusion. However, SCP-0.5 g and SCP-1 g treatments effectively reversed ZO-1 and ZO-3 but did not affect ZO-2 expression in the cortical penumbra $3 \mathrm{~d}$ after reperfusion. Moreover, our Western blot, IHC, and IF double staining data revealed that ZO-1 was colocalized with ICAM1 , and the expression patterns of $\mathrm{ZO}-1$ in the experimental groups were consistent with those of ICAM-1/ MMP-9/VEGF-A signaling. The aforementioned results suggest that $\mathrm{ZO}-1$ and $\mathrm{ZO}-3$ play roles in the 


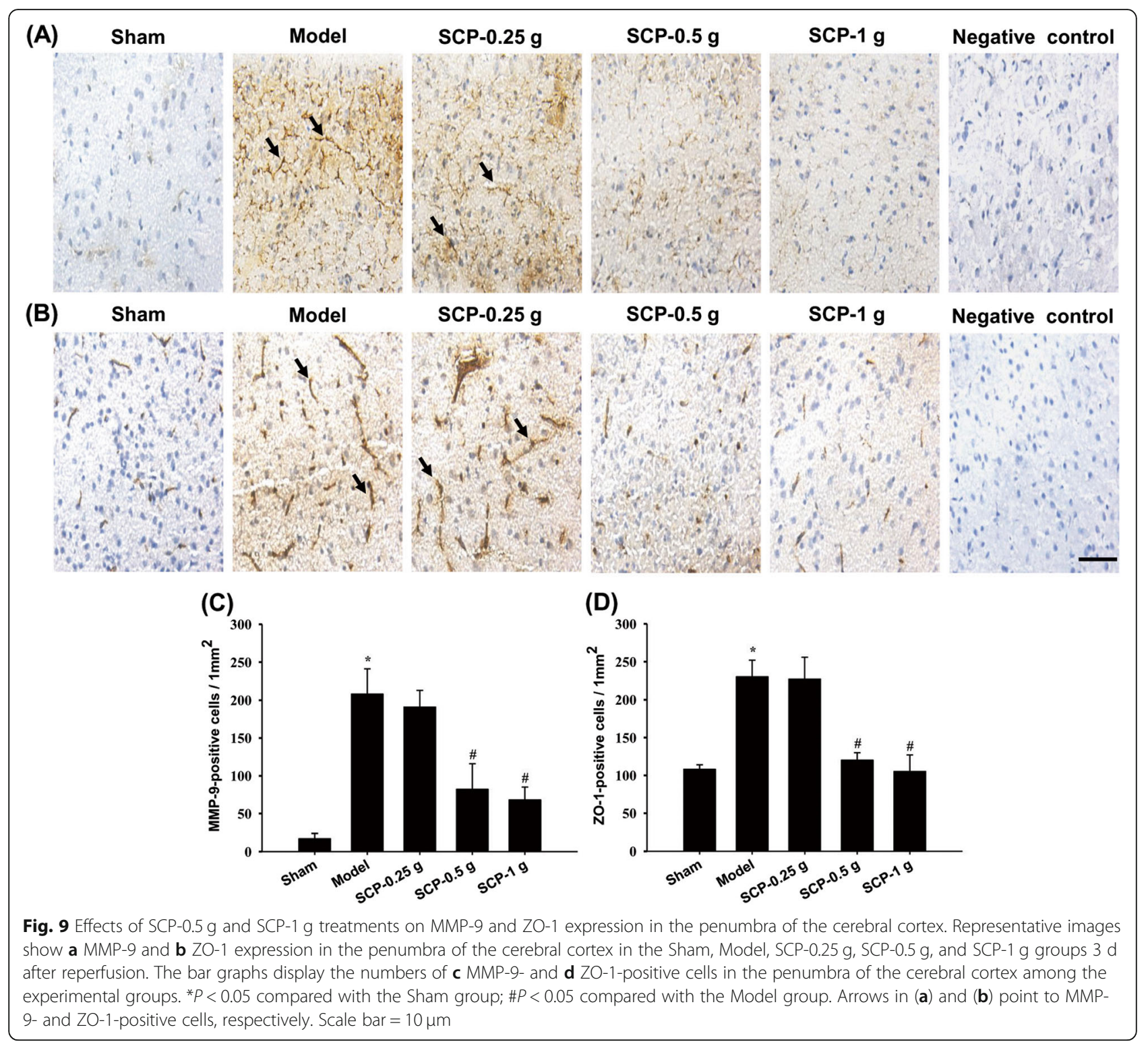

enhancement of endothelial chemotaxis and maintenance of TJ integrity, respectively in the cortical penumbra $3 \mathrm{~d}$ after reperfusion. In the initial stage of cerebral I/R injury, endothelial TJ disruption is partially induced by activating ICAM-1/MMP-9/VEGF-A signaling in the ischemic area. Later, this cascade triggers ZO-1 overexpression, which further elicits the chemotactic activity of leukocyte infiltration into endothelial cells, exacerbating cerebral edema. Further analysis indicates that the effects of SCP extract treatments on vasogenic edema are partially mediated by the downregulation of JNK/iNOS-mediated ICAM-1/ MMP-9/VEGF-A/ZO-1 and the upregulation of ZO-3 signaling in the penumbra of cerebral cortex $3 \mathrm{~d}$ after reperfusion. To our knowledge, this is the first study to report the positive relationship between $\mathrm{ZO}-1$ and ICAM-1 expression in vascular endothelial cells in the ischemic area following cerebral $\mathrm{I} / \mathrm{R}$ injury. However, the precise mechanisms underlying $\mathrm{TJ}$ integrity preservation by ZO-3 still need to be elucidated.

\section{Conclusions}

Taken together, the study results revealed that the SCP extract administered at doses of $0.5 \mathrm{~g} / \mathrm{kg}$ and $1 \mathrm{~g} / \mathrm{kg}$ markedly reduced cerebral infarction, alleviated cerebral edema, and restored neurological function in the early phase of transient MCAo. The effects of SCP extract treatments on cerebral $I / R$ injury-induced cerebral edema are partially due to the inhibition of astrocytic swelling and $\mathrm{BBB}$ disruption in the cortical penumbra. 

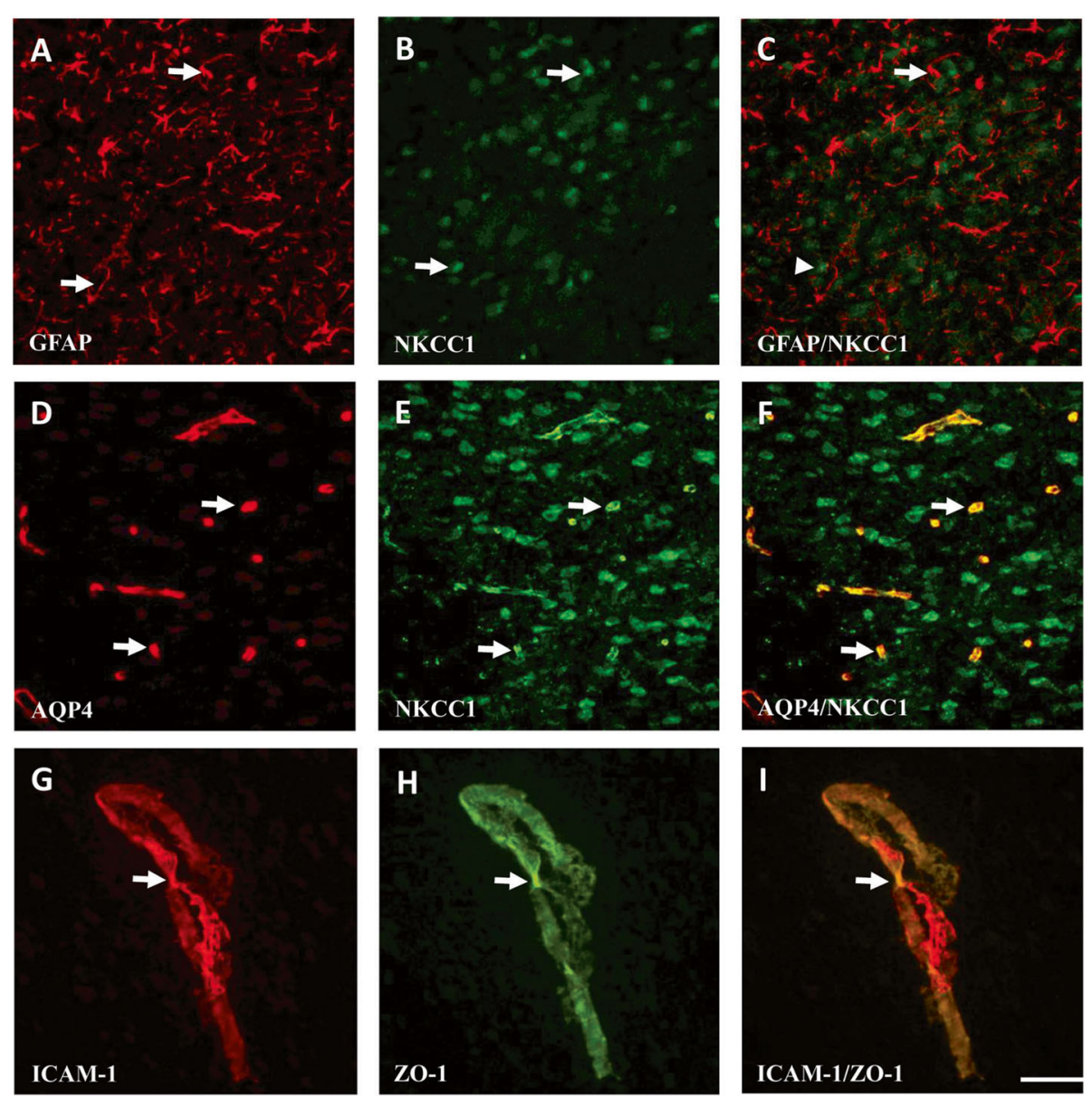

Fig. 10 Expression of GFAP-, NKCC1-, AQP4-, ICAM-1-, and ZO-1-positive cells in the penumbra of the cerebral cortex. Arrows in (a), (b), (d), (e), (g), and (h) point to GFAP-, NKCC1-, AQP4-, NKCC1-, ICAM-1-, and ZO-1-positive cells, respectively, in the penumbra of the cerebral cortex. The arrow and arrowhead in (c) point to GFAP- and NKCC1-positive cells, respectively. Arrows in (f) and (i) point to AQP4/NKCC1 and ICAM-1/ZO-1 double-labeled cells, respectively. Scale bar $=50 \mu \mathrm{m}$

Furthermore, the anti-edema effects of SCP extract treatments are possibly associated with the downregulation of astrocytic NKCC1/AQP4 and JNK/iNOS-mediated ICAM-1/MMP-9 signaling in the penumbra of the cerebral cortex $3 \mathrm{~d}$ after reperfusion. Thus, the results of this study indicate that the A. tatarinowii Schott extract can be a therapeutic agent for reducing cerebral edema after cerebral I/R injury. However, further research is required to elucidate precise mechanisms underlying the anti-cerebral edema effects of the A. tatarinowii Schott extract for future clinical applications.

\section{Abbreviations}

SCP: Acorus tatarinowii Schott (Shi Chang Pu); MCAo: Middle cerebral artery occlusion; KCC1: $\mathrm{Na}^{+}-\mathrm{K}^{+}-2 \mathrm{Cl}^{-}$cotransporter type 1; AQP4: Aquaporin 4; JNK: c-Jun N-terminal kinase; iNOS: Inducible nitric oxide synthase; ICAM1: Intercellular adhesion molecule-1; MMP-9: Matrix metalloproteinase-9; VEGF-A: Vascular endothelial growth factor-A; ZO-1: Zonula occluden-1; BBB: Blood-brain barrier; I/R: Ischemia-reperfusion; NO: Nitric oxide; GFAP: Glial fibrillary acidic protein; MAPK: Mitogen-activated protein kinase; iNOS: Inducible nitric oxide synthase; 3-NT: 3-nitrotyrosine; TJ: Tight junction;
HPLC: High performance liquid chromatography; MCA: Middle cerebral artery; ECA: External carotid artery; ICA: Internal carotid artery;

mNSS: Modified neurological severity score; TTC: 2,3,5-triphenyltetrazolium chloride; EBD: Evans blue dye; RT: Room temperature; NC: Nitrocellulose; IHC: Immunohistochemical; IF: Immunofluorescence

\section{Acknowledgements}

We thank Miss Shu-Tuan Chiang for kindly helping with HPLC analysis.

\section{Authors' contributions}

YCL and CYC designed experiments. CYC performed experiments, analyzed data and wrote the manuscript. STK helped to draft the manuscript. All authors read and approved the final manuscript.

\section{Funding}

This study was supported by grants from the Ministry of Science and Technology of Taiwan (MOST 107-2320-B-039-027-) and China Medical University Hospital (DMR-108-008), Taichung, Taiwan. These funding sources had no role in the design of the study and collection, analysis, and interpretation of the data and in writing the manuscript.

\section{Availability of data and materials}

The datasets used and/or analysed during the current study are available from the corresponding author on reasonable request. 


\section{Ethics approval and consent to participate}

All surgical and experimental procedures were approved by the Institutional Animal Care and Use Committee of China Medical University (Permit Number: CMUIACUC-2018-304). The committee has recognized that the research methodologies and designs followed the Animal Protection Act by the Council of Agriculture, Taiwan. All surgical and experimental procedures were designed to avoid or minimize discomfort, distress, and pain to the animals.

\section{Consent for publication}

Not applicable.

\section{Competing interests}

The authors have declared that no competing interests exist.

\section{Author details}

'Graduate Institute of Acupuncture Science, China Medical University, Taichung 40402, Taiwan. ${ }^{2}$ Department of Chinese Medicine, China Medical University Hospital 40447, Taichung, Taiwan. ${ }^{3}$ Research Center for Chinese Medicine \& Acupuncture, China Medical University, Taichung 40402, Taiwan. ${ }^{4}$ School of Chinese Medicine, College of Chinese Medicine, China Medical University, Taichung 40402, Taiwan. ${ }^{5}$ School of Post-baccalaureate Chinese Medicine, College of Chinese Medicine, China Medical University, Taichung 40402, Taiwan. ${ }^{6}$ Department of Chinese Medicine, Hui-Sheng Hospital 42056, Taichung, Taiwan.

Received: 31 March 2020 Accepted: 26 November 2020 Published online: 09 December 2020

\section{References}

1. Wicha P, Tocharus J, Janyou A, Jittiwat J, Changtam C, Suksamrarn A, Tocharus C. Hexahydrocurcumin protects against cerebral ischemia/ reperfusion injury, attenuates inflammation, and improves antioxidant defenses in a rat stroke model. PLoS One. 2017;12(12):e0189211.

2. Kleindienst A, Dunbar JG, Glisson R, Marmarou A. The role of vasopressin $\mathrm{V} 1 \mathrm{~A}$ receptors in cytotoxic brain edema formation following brain injury. Acta Neurochir. (Wien). 2013;155(1):151-64.

3. Huang L, Cao W, Deng Y, Zhu G, Han Y, Zeng H. Hypertonic saline alleviates experimentally induced cerebral oedema through suppression of vascular endothelial growth factor and its receptor VEGFR2 expression in astrocytes. BMC Neurosci. 2016;17(1):64.

4. Kondo T, Reaume AG, Huang TT, Murakami K, Carlson E, Chen S, Scott RW Epstein CJ, Chan PH. Edema formation exacerbates neurological and histological outcomes after focal cerebral ischemia in CuZn-superoxide dismutase gene knockout mutant mice. Acta Neurochir Suppl. 1997;70:62-4.

5. Wu H, Tang C, Tai LW, Yao W, Guo P, Hong J, Yang X, Li X, Jin Z, Ke J, et al. Flurbiprofen axetil attenuates cerebral ischemia/reperfusion injury by reducing inflammation in a rat model of transient global cerebral ischemia/ reperfusion. Biosci Rep. 2018;38(4):1-12.

6. Li M, Ma RN, Li LH, Qu YZ, Gao GD. Astragaloside IV reduces cerebral edema post-ischemia/reperfusion correlating the suppression of MMP-9 and AQP4. Eur J Pharmacol. 2013;15(1-3):189-95.

7. Papadopoulos MC, Verkman AS. Quaporin water channels in the nervous system. Nat Rev Neurosci. 2013;14(4):265-77.

8. Lafrenaye AD, Simard JM. Bursting at the Seams: Molecular Mechanisms Mediating Astrocyte Swelling. Int J Mol Sci. 2019;20(2):330.

9. Yan Y, Dempsey RJ, Sun D. Na+-K+-cl-cotransporter in rat focal cerebral ischemia. J Cereb Blood Flow Metab. 2001;21(6):711-21.

10. Simard JM, Kahle KT, Gerzanich V. Molecular mechanisms of microvascular failure in central nervous system injury--synergistic roles of NKCC1 and SUR1/TRPM4. J Neurosurg. 2010;113(3):622-9.

11. Vella J, Zammit C, Di Giovanni G, Muscat R, Valentino M. The central role of aquaporins in the pathophysiology of ischemic stroke. Front Cell Neurosci. 2015;9:108.

12. Benarroch EE. Neuron-astrocyte interactions: partnership for normal function and disease in the central nervous system. Mayo Clin Proc. 2005;80(10): 1326-38.

13. Stokum JA, Kurland DB, Gerzanich V, Simard JM. Mechanisms of astrocytemediated cerebral edema. Neurochem Res. 2015;40(2):317-28.

14. Wang YF, Parpura V. Central role of maladapted Astrocytic plasticity in ischemic brain edema formation. Front Cell Neurosci. 2016;10:129.
15. Wang YH, Wang WY, Chang CC, Liou KT, Sung YJ, Liao JF, Chen CF, Chang S, Hou YC, Chou YC, et al. Taxifolin ameliorates cerebral ischemiareperfusion injury in rats through its anti-oxidative effect and modulation of NF-kappa B activation. J Biomed Sci. 2006;13(1):127-41.

16. Sun L, Yang L, Fu Y, Han J, Xu Y, Liang H, Cheng Y. Capacity of HSYA to inhibit nitrotyrosine formation induced by focal ischemic brain injury. Nitric Oxide. 2013;35:144-51.

17. Atochin DN, Schepetkin IA, Khlebnikov Al, Seledtsov VI, Swanson H, Quinn MT, Huang PL. A novel dual NO-donating oxime and c-Jun N-terminal kinase inhibitor protects against cerebral ischemia-reperfusion injury in mice. Neurosci Lett. 2016;618:45-9.

18. Khan M, Dhammu TS, Sakakima H, Shunmugavel A, Gilg AG, Singh AK, Singh I. The inhibitory effect of S-nitrosoglutathione on blood-brain barrier disruption and peroxynitrite formation in a rat model of experimental stroke. J Neurochem. 2012;123(Suppl 2):86-97.

19. Ahsan H. 3-Nitrotyrosine: a biomarker of nitrogen free radical species modified proteins in systemic autoimmunogenic conditions. Hum Immunol. 2013;74(10):1392-9.

20. Takemori $\mathrm{K}$, Ito $\mathrm{H}$, Suzuki T. Effects of the AT1 receptor antagonist on adhesion molecule expression in leukocytes and brain microvessels of stroke-prone spontaneously hypertensive rats. Am J Hypertens. 2000;13(11): 1233-41.

21. Dong X, Song YN, Liu WG, Guo XL. Mmp-9, a potential target for cerebral ischemic treatment. Curr Neuropharmacol. 2009;7(4):269-75.

22. Restin T, Kajdi ME, Schlapfer M, Roth Z'graggen B, Booy C, Dumrese C, BeckSchimmer B. Sevoflurane protects rat brain endothelial barrier structure and function after hypoxia-reoxygenation injury. PLoS One. 2017;12(10): e0184973.

23. Yang $M$, Chen $Y$, Wu Z, Zhang $Y$, Cai R, Ye L, Huang $Y$, Wang L, He $H$. The impact of chronic intermittent hypoxia on the expression of intercellular cell adhesion molecule-1 and vascular endothelial growth factor in the ischemia-reperfusion rat model. Folia Neuropathol. 2018; 56(3):159-66.

24. Zhang HT, Zhang P, Gao Y, Li CL, Wang HJ, Chen LC, Feng Y, Li RY, Li YL, Jiang CL. Early VEGF inhibition attenuates blood-brain barrier disruption in ischemic rat brains by regulating the expression of MMPs. Mol Med Rep. 2017:5(1):57-64

25. Greene C, Campbell M. Tight junction modulation of the blood brain barrier: CNS delivery of small molecules. Tissue Barriers. 2016;4(1):e1138017.

26. Ahmad A, Genovese T, Impellizzeri D, Crupi R, Velardi E, Marino A, Esposito E, Cuzzocrea S. Reduction of ischemic brain injury by administration of palmitoylethanolamide after transient middle cerebral artery occlusion in rats. Brain Res. 2012;1477:45-58.

27. Zhu M, Zhu H, Tan N, Zeng G, Zeng Z, Chu H, Wang H, Xia Z, Wu R. The effects of Acorus tatarinowii Schott on 5-HT concentrations, TPH2 and 5HT1B expression in the dorsal raphe of exercised rats. J Ethnopharmacol. 2014:158 Pt A:431-6.

28. Lam KYC, Wu QY, Hu WH, Yao P, Wang HY, Dong TTX, Tsim KWK. Asarones from Acori Tatarinowii Rhizoma stimulate expression and secretion of neurotrophic factors in cultured astrocytes. Neurosci Lett. 2019;707:134308.

29. Zuo HL, Yang FQ, Zhang XM, Xia ZN. Separation of cis- and trans-Asarone from Acorus tatarinowii by preparative gas chromatography. J Anal Methods Chem. 2012;2012:402081.

30. Lee HJ, Ahn SM, Pak ME, Jung DH, Lee SY, Shin HK, Choi BT. Positive effects of alpha-asarone on transplanted neural progenitor cells in a murine model of ischemic stroke. Phytomedicine. 2018;51:151-61.

31. Mo ZT, Fang YQ, He YP, Zhang S. Beta-Asarone protects PC12 cells against OGD/R-induced injury via attenuating Beclin-1-dependent autophagy. Acta Pharmacol. Sin. 2012:33(6):737-42.

32. Lee B, Choi Y, Kim H, Kim SY, Hahm DH, Lee HJ, Shim I. Protective effects of methanol extract of Acori graminei rhizoma and Uncariae Ramulus et Uncus on ischemia-induced neuronal death and cognitive impairments in the rat. Life Sci. 2003;74(4):435-50.

33. Unger $P$, Melzig MF. Comparative study of the cytotoxicity and genotoxicity of alpha- and Beta-asarone. Sci Pharm. 2012;80(3):663-8.

34. Lam KY, Chen J, Lam CT, Wu Q, Yao P, Dong T, Lin H, Tsim KW. Asarone from Acori Tatarinowii Rhizoma potentiates the nerve growth factor-induced neuronal differentiation in cultured PC12 cells: a signaling mediated by protein kinase a. PLoS One. 2016;11(9): e0163337. 
35. Yang YX, Chen YT, Zhou XJ, Hong CL, Li CY, Guo JY. Beta-asarone, a major component of Acorus tatarinowii Schott, attenuates focal cerebral ischemia induced by middle cerebral artery occlusion in rats. BMC Complement Altern Med. 2013;13:236.

36. Yang GY, Chen SF, Kinouchi H, Chan PH, Weinstein PR. Edema, cation content, and ATPase activity after middle cerebral artery occlusion in rats. Stroke. 1992;23(9):1331-6.

37. Haghnejad Azar A, Oryan S, Bohlooli S, Panahpour H. Alpha-tocopherol reduces brain edema and protects blood-brain barrier integrity following focal cerebral ischemia in rats. Med Princ Pract. 2017;26(1):17-22.

38. Zhan C, Yang J. Protective effects of isoliquiritigenin in transient middle cerebral artery occlusion-induced focal cerebral ischemia in rats. Pharmacol Res. 2006;53(3):303-9.

39. Cheng CY, Ho TY, Hsiang CY, Tang NY, Hsieh CL, Kao ST, Lee YC. Angelica sinensis exerts Angiogenic and anti-apoptotic effects against cerebral ischemia-reperfusion injury by activating p38MAPK/HIF-1[formula: see text]/ VEGF-A signaling in rats. Am J Chin Med. 2017;45(8):1683-708.

40. Chen J, Sanberg PR, Li Y, Wang L, Lu M, Willing AE, Sanchez-Ramos J, Chopp M. Intravenous administration of human umbilical cord blood reduces behavioral deficits after stroke in rats. Stroke. 2001;32(11):2682-8.

41. Yen LF, Wei VC, Kuo EY, Lai TW. Distinct patterns of cerebral extravasation by Evans blue and sodium fluorescein in rats. PLoS One. 2013;8(7):e68595.

42. Cheng CY, Lin JG, Tang NY, Kao ST, Hsieh CL. Electroacupuncture-like stimulation at the Baihui (GV20) and Dazhui (GV14) acupoints protects rats against subacute-phase cerebral ischemia-reperfusion injuries by reducing S100B-mediated neurotoxicity. PLoS One. 2014;9(3):e91426.

43. Qiu $Y$, Yin Q, Fei $Y$, Li Y, Huang $H$, Fang $W$, Shen W, Liang B, Zhu X ILX001 modulated the inflammatory reaction and oxidative stress in PMCAO rats via inhibiting the TLR2/4-NF-kappaB signaling pathway. Neurochem Res. 2019;44(8):1924-38.

44. Fukuda AM, Badaut J. Aquaporin 4: a player in cerebral edema and neuroinflammation. J Neuroinflammation. 2012;9:279.

45. Matsuo Y, Mihara S, Ninomiya M, Fujimoto M. Protective effect of endothelin type a receptor antagonist on brain edema and injury after transient middle cerebral artery occlusion in rats. Stroke. 2001;32(9):2143-8.

46. Cheng CY, Lin JG, Tang NY, Kao ST, Hsieh CL. Electroacupuncture at different frequencies $(5 \mathrm{~Hz}$ and $25 \mathrm{~Hz})$ ameliorates cerebral ischemiareperfusion injury in rats: possible involvement of p38 MAPK-mediated antiapoptotic signaling pathways. BMC Complement Altern Med. 2015;15:241.

47. Rathnasamy G, Ling EA, Kaur C. Therapeutic implications of melatonin in cerebral edema. Histol Histopathol. 2014;29(12):1525-38.

48. Previch LE, Ma L, Wright JC, Singh S, Geng X, Ding Y. Progress in AQP Research and New Developments in Therapeutic Approaches to Ischemic and Hemorrhagic Stroke. Int J Mol Sci. 2016;17(7):1146.

49. Wang CC, Chio CC, Chang CH, Kuo JR, Chang CP. Beneficial effect of agmatine on brain apoptosis, astrogliosis, and edema after rat transient cerebral ischemia. BMC Pharmacol. 2010;10:11.

50. Hoshi A, Yamamoto T, Shimizu K, Sugiura Y, Ugawa Y. Chemical preconditioning-induced reactive astrocytosis contributes to the reduction of post-ischemic edema through aquaporin-4 downregulation. Exp Neurol. 2011;227(1):89-95.

51. O'Donnell ME, Tran L, Lam TI, Liu XB, Anderson SE. Bumetanide inhibition of the blood-brain barrier $\mathrm{Na}-\mathrm{K}-\mathrm{cl}$ cotransporter reduces edema formation in the rat middle cerebral artery occlusion model of stroke. J Cereb Blood Flow Metab. 2004;24(9):1046-56.

52. Shi Z, Zhang W, Lu Y, Xu L, Fang Q, Wu M, Jia M, Wang Y, Dong L, Yan X, et al. Aquaporin 4-mediated glutamate-induced astrocyte swelling is partially mediated through metabotropic glutamate receptor 5 activation. Front Cell Neurosci. 2017:11:116.

53. Benakis C, Bonny C, Hirt L. JNK inhibition and inflammation after cerebral ischemia. Brain Behav Immun. 2010;24(5):800-11.

54. Yamaguchi M, Okamoto K, Kusano T, Matsuda Y, Suzuki G, Fuse A, Yokota H. The effects of xanthine Oxidoreductase inhibitors on oxidative stress markers following global brain ischemia reperfusion injury in C57BL/6 mice. PLoS One. 2015;10(7):e0133980

55. Liu Y, Wang D, Wang H, Qu Y, Xiao X, Zhu Y. The protective effect of HET0016 on brain edema and blood-brain barrier dysfunction after cerebral ischemia/reperfusion. Brain Res. 2014;1544:45-53.

56. Panahpour H, Nekooeian AA, Dehghani GA. Candesartan attenuates ischemic brain edema and protects the blood-brain barrier integrity from ischemia/reperfusion injury in rats. Iran Biomed J. 2014;18(4):232-8.
57. Oh TW, Park KH, Jung HW, Park YK. Neuroprotective effect of the hairy root extract of Angelica gigas NAKAI on transient focal cerebral ischemia in rats through the regulation of angiogenesis. BMC Complement Altern Med. 2015;15:101.

58. Zhang $Y$, Yang WX. Tight junction between endothelial cells: the interaction between nanoparticles and blood vessels. Beilstein J Nanotechnol. 2016;7: 675-84.

59. Mark KS, Davis TP. Cerebral microvascular changes in permeability and tight junctions induced by hypoxia-reoxygenation. Am J Physiol Heart Circ Physiol. 2002;282(4):H1485-94.

60. Itoh M, Furuse M, Morita K, Kubota K, Saitou M, Tsukita S. Direct binding of three tight junction-associated MAGUKs, ZO-1, ZO-2, and ZO-3, with the $\mathrm{COOH}$ termini of claudins. J Cell Biol. 1999;147(6):1351-63.

61. Lee JF, Zeng Q, Ozaki H, Wang L, Hand AR, Hla T, Wang E, Lee MJ. Dual roles of tight junction-associated protein, zonula occludens-1, in sphingosine 1-phosphate-mediated endothelial chemotaxis and barrier integrity. J Biol Chem. 2006;281(39):29190-200.

62. Zan L, Zhang X, Xi Y, Wu H, Song Y, Teng G, Li H, Qi J, Wang J. Src regulates angiogenic factors and vascular permeability after focal cerebral ischemiareperfusion. Neuroscience. 2014;262:118-28.

\section{Publisher's Note}

Springer Nature remains neutral with regard to jurisdictional claims in published maps and institutional affiliations.
Ready to submit your research? Choose BMC and benefit from:

- fast, convenient online submission

- thorough peer review by experienced researchers in your field

- rapid publication on acceptance

- support for research data, including large and complex data types

- gold Open Access which fosters wider collaboration and increased citations

- maximum visibility for your research: over $100 \mathrm{M}$ website views per year

At BMC, research is always in progress.

Learn more biomedcentral.com/submissions 